\title{
Images from the Haematologica Atlas of Hematologic Cytology: pure erythroid leukemia
}

\section{Rosangela Invernizzi}

University of Pavia, Pavia, Italy

E-mail: ROSANGELA INVERNIZZI - rosangela.invernizzi@unipv.it

doi:10.3324/haematol.2021.279628

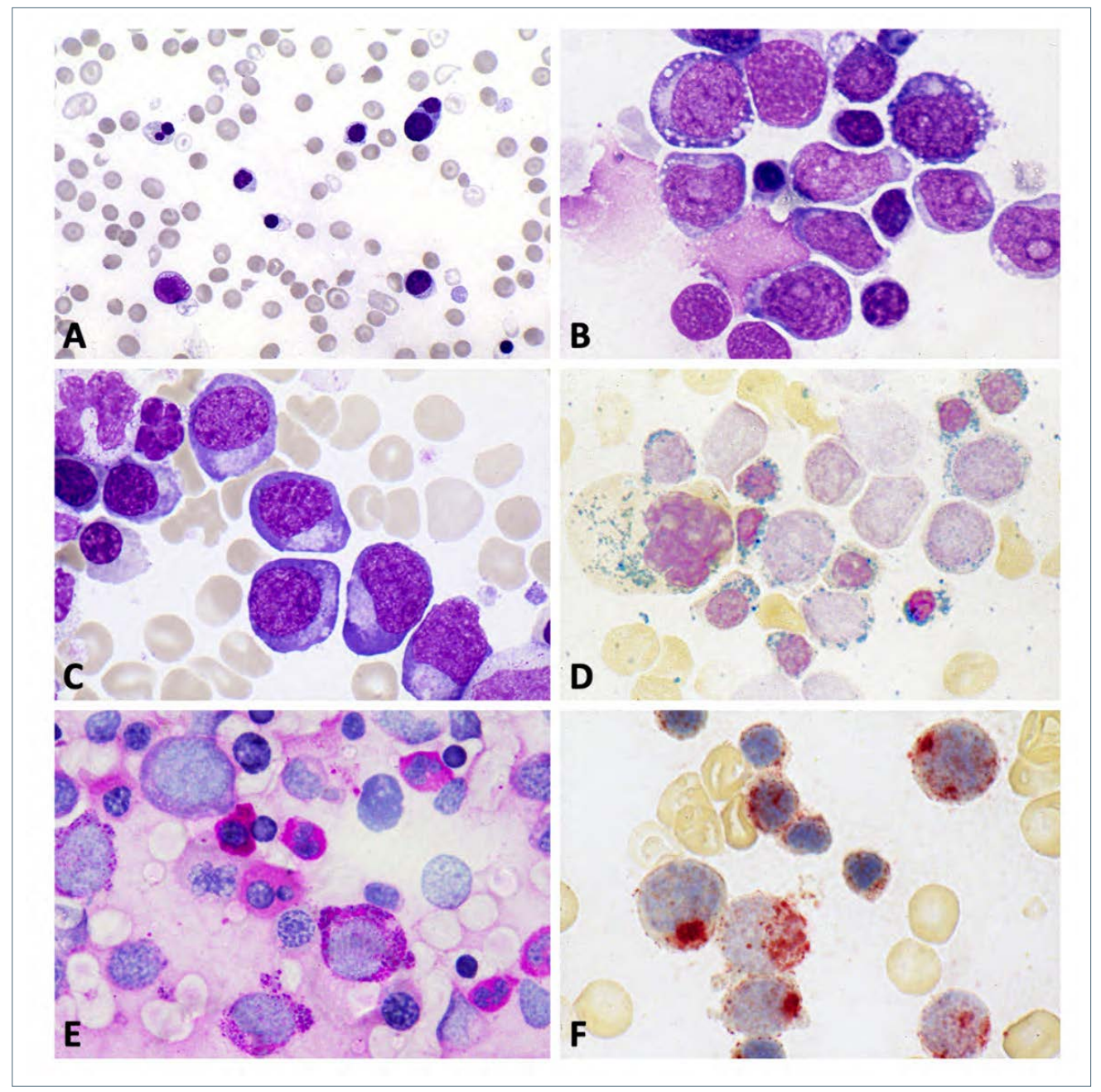

$\mathrm{P}$ ure erythroid leukemia (French-American-British classification M6) is characterized by $>80 \%$ of erythroid precursors in the bone marrow with $\geq 30 \%$ proerythroblasts and a non-significant myeloblastic component. Morphological features of this extremely rare entity are shown in the Figure. Remarkable anisopoikilocytosis of red cells and numerous morphologically abnormal erythroblasts are commonly observed in the peripheral blood (A). Bone marrow is infiltrated by very immature and atypical erythroid precursors. These large cells have round nuclei with reticular chromatin and prominent nucleolus, and hyperbasophilic, agranular, often vacuolated cytoplasm (B) or megaloblastic features and a voluminous paranuclear clear area (C). Leukemic erythroblasts are negative for myeloperoxidase and Sudan black B staining, while Perls' reaction may show several ring sideroblasts (D) and periodic-acid Schiff (PAS) stain is strongly positive with a granular pattern in the early erythroid precursors and a diffuse pattern in late erythroblasts (E). Atypical erythroid precursors show localized paranuclear reactivity for acid phosphatase (F). ${ }^{1}$

\section{Disclosures}

No conflicts of interest to disclose.

\section{Reference}

1. Invernizzi R. Acute myeloid leukemia and related precursor neoplasms. Haematologica. 2020;105(Suppl1):98-119. 